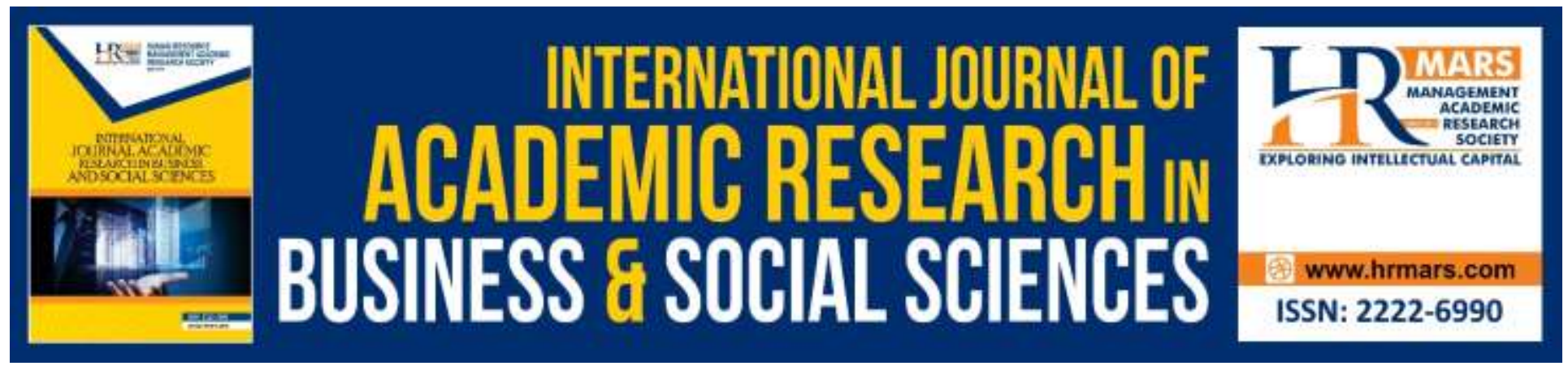

\title{
A Systematic Literature Review Studies on George Town Festival (2010-2019)
}

Dina Miza Suhaimi, Reevany Bustami

To Link this Article: http://dx.doi.org/10.6007/IJARBSS/v10-i5/7318

DOI:10.6007/IJARBSS/v10-i5/7318

Received: 12 March 2020, Revised: 16 April 2020, Accepted: 29 April 2020

Published Online: 20 May 2020

In-Text Citation: (Suhaimi \& Bustami, 2020)

To Cite this Article: Suhaimi, D. M., \& Bustami, R. (2020). A Systematic Literature Review Studies on George Town Festival (2010-2019). International Journal of Academic Research in Business and Social Sciences, 10(5), 869878.

Copyright: (c) 2020 The Author(s)

Published by Human Resource Management Academic Research Society (www.hrmars.com)

This article is published under the Creative Commons Attribution (CC BY 4.0) license. Anyone may reproduce, distribute, translate and create derivative works of this article (for both commercial and non-commercial purposes), subject to full attribution to the original publication and authors. The full terms of this license may be seen at: http://creativecommons.org/licences/by/4.0/legalcode

Vol. 10, No. 5, 2020, Pg. 869 - 878

Full Terms \& Conditions of access and use can be found at http://hrmars.com/index.php/pages/detail/publication-ethics 


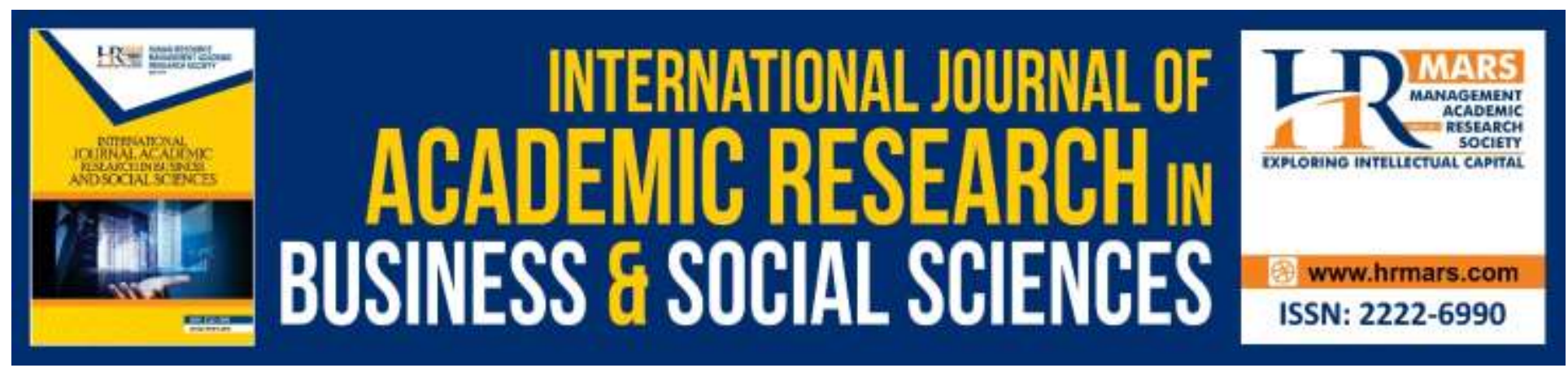

\title{
A Systematic Literature Review Studies on George Town Festival (2010-2019)
}

\author{
Dina Miza Suhaimi ${ }^{1,2}$ Reevany Bustami ${ }^{1}$ \\ ${ }^{1}$ Center for Policy Research and International Studies, Universiti Sains Malaysia, 11800, Penang, \\ Malaysia, ${ }^{2}$ Faculty of Technical and Vocational, Universiti Pendidikan Sultan Idris, 35900, \\ Tanjong Malim, Perak
}

\begin{abstract}
George Town Festival (GTF) is a month-long festival that commemorates the inscription of George Town as a Cultural World Heritage Site (CWHS) by UNESCO in July 7, 2008. Inaugurated in 2009, the festival was scheduled to be an annual event. The objectives of GTF are three-fold: (i) to celebrate UNESCO George Town Cultural World Heritage Site (the Site) and to showcase the unique diversity of local culture and heritage; (ii) to present an annual international festival to showcase local and international performances and enrich the cultural environment of Penang; and (iii) to serve as a catalyst in raising wider public interest in the arts and to encourage cultural exchange and dialogue. Nevertheless, since the commencement of GTF between 2010 and 2019, much has been debated that the festival lacks of local representations. Despite its controversial debate, very few studies had been carried out. Hence, the aim of this present study is to systematically review a considerable amount of past studies about GTF. The paper utilised two main journal databases, namely Scopus and Google Scholar. Accordingly, the searching efforts resulted in a total of sixteen articles that can be analysed systematically.
\end{abstract}

Keywords: George Town Festival, Penang, Malaysia, Ethnicity, Systematic Literature Review (SLR)

\section{Introduction}

In 2008, George Town, Penang, Malaysia was inscribed as UNESCO Cultural World Heritage Site. The prestigious inscription was based on three cultural criteria, namely (ii) multi-cultural history; (iii) living multi-cultural traditions; and (iv) multi-cultural townscape (Musa \& Feng, 2016). Since the inscription in 2008, many events have been organized to commemorate George Town for its prestigious cultural heritage status. Such events include George Town Heritage Day, George Town Heritage Celebration, George Town Literally Festival, the In Between Festival (IBaF), George Town Festival, to name a few. Among all, George Town Festival (GTF) is unique as it runs for a month, annually. The festival aims to (Sidek, 2011) to (i) celebrate George Town as a UNESCO Cultural World Heritage Site and to showcase the unique diversity of local culture and heritage (GTF 2019; Bideau \& Kilani, 2012); (ii) present as an annual international festival to showcase 
both local and international performances and enrich the cultural environment of Penang; and (iii) serve as a catalyst in raising wider public interest in the arts and to encourage cultural exchanges (Cultural Transitions: George Town, 2012).

It is noteworthy that the GTF aims to be an international platform for the locals to showcase Penang and Malaysian unique traditions and cultures for the future generation.Since the inauguration of the GTF in 2010 up to the present time, it has featured cultural exhibitions, and representations by the various ethnic communities (Merican et al.; 2018). However, since the commencement of GTF from 2010 until 2019, only a few studies on GTF had been carried out. Considering very limited number of existing systematic review related to George Town Festival studies, hence, the current paper attempts to systematically review all the relevant literature on GTF from 2010 until present. The systematic review offers several advantages compared to the conventional style literature reviews. The reviews can be strengthened via a transparent article retrieving process, a more prominent wider area of research, more significant objectives which can control research bias. Apart from that, this also motivates the researcher to produce quality evidence with more significant results (Mallet et al., 2012, in Shaffril et al., 2019).

\section{Material and Method: The systematic review process for selecting the articles}

This section explains the systematic review process. The review is based on systematic literature review (SLR) with special reference to George Town Festival (GTF). This paper applied online searching approach to navigate available sources from Scopus and supported by Google Scholar databases. Since the month-long GTF was established since 2010, articles included in this paper consist of which have been published between 2010 and 2019. Specifically, Scopus indexes a total of fifty-seven journals, while Google Scholar indexes forty-seven journals related to GTF.

The systematic review analysis is replicable, scientific and transparent method of literature review. This method can minimize bias on literature review as it provides comprehensive decisions, procedures and conclusion from researchers (Wolf et al.; 2001). The methodology for a systematic literature in selecting articles includes identification, screening and eligibility (Shaffril et al., 2019).

\section{Identification}

Generally, the systematic review process in selecting a number of most relevant articles consisted of three-tier phases. The first phase is the identification of keywords, followed by the process of searching for related and similar terms based on the keywords of past researches. For this paper, the Scopus search strings were successfully retrieved a total of fifty-seven articles ${ }^{1}$. As mentioned above, this paper is supported by Google Scholar database, and based on the exact phrase of

\footnotetext{
1 TITLE-ABS-KEY ( ( "george town festival*" OR "georgetown festival*" OR "gtf" OR "cultural festival*" OR "cultural heritage festival*" OR "street art*" OR "mural*" OR "wall art*" OR "graffiti*" OR "cultural festival*" OR "cultural event*" OR "heritage event") AND ( "penang" OR "pulau pinang" OR "george town world heritage site" OR "george town" OR "george town heritage" OR "heritage site" OR "heritage city" ) )
} 
George Town Festival, an additional number of forty-seven articles were retrieved. In total, 104 articles were retrieved in the first phase of the systematic review process ${ }^{2}$.

\section{Screening}

The purpose of the first phase of screening was to screen that 104 articles based on several inclusion and exclusion criteria determined by the researchers. The first criterion was review on articles that were published in 2010 onwards. Additionally, only studies conducted in Malaysia were selected. Overall, a total of fifty-two articles were excluded based on these criteria.

\section{Eligibility}

A total of fifty-two articles were prepared for the eligibility phase. At this phase, on a more important note, the titles, abstracts, and the main contents of all the articles were examined thoroughly to ensure that they fulfilled the inclusion criteria and fit to be employed in the present study in order to achieve the objectives of the current research. Consequently, a total of thirtyfive articles were excluded because they are not focused on George Town Festival in Penang, Malaysia. As a final point, a total of sixteen remaining articles are ready to be analysed (see Figure 1: Scopus and Google Scholar SLR flowchart on GTF).

2 Google Scholar advanced search 'with exact phrase': "George town festival" 
INTERNATIONAL JOURNAL OF ACADEMIC RESEARCH IN BUSINESS AND SOCIAL SCIENCES

Vol. 10, No. 5, May, 2020, E-ISSN: $2222-6990$ ๑ 2020 HRMARS

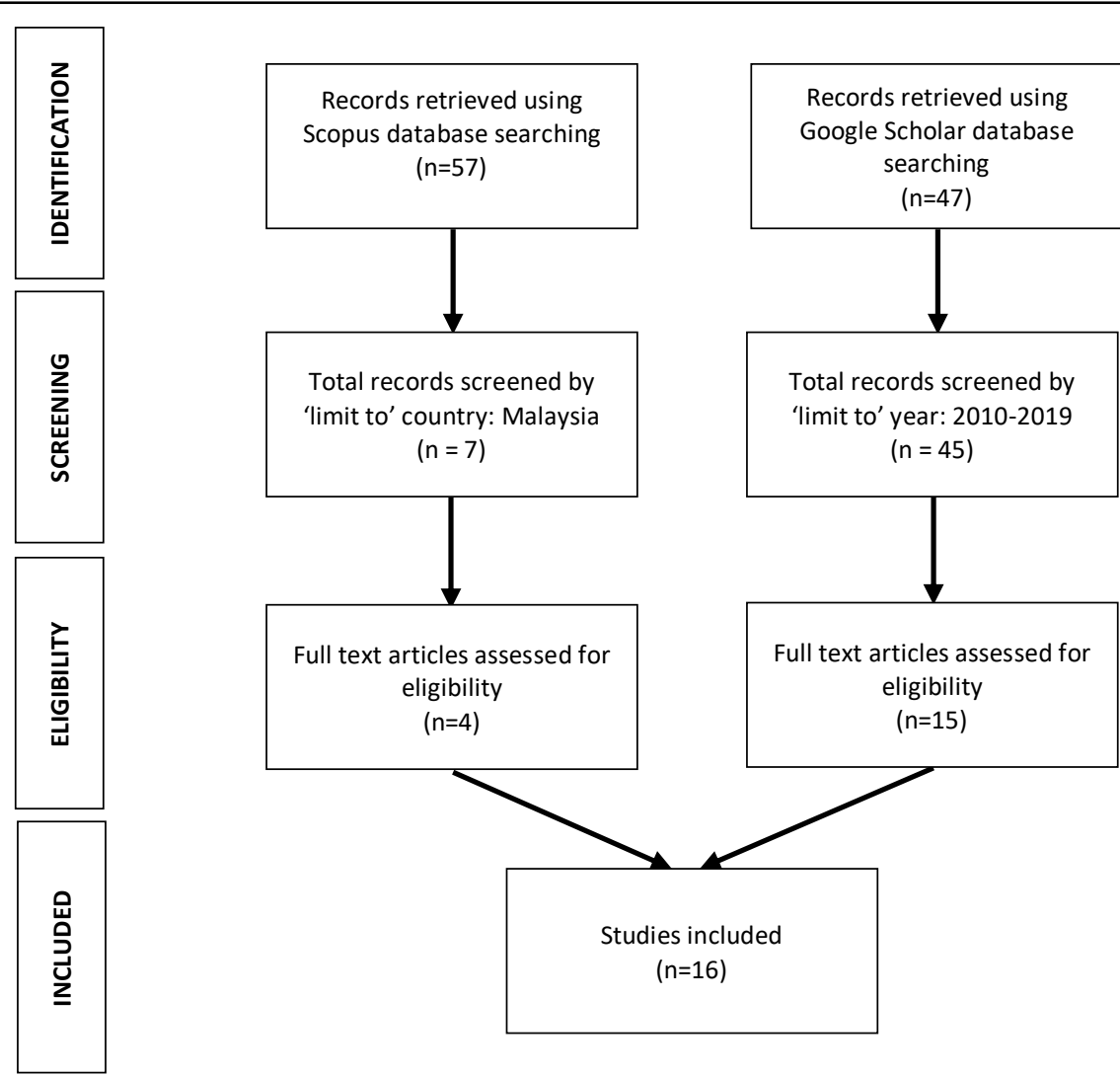

Figure 1. Scopus and Google Scholar SLR flowchart on GTF

(Moher et al., 2009)

\section{Findings}

The analysis of sixteen articles produced a total of three themes and seventeen sub-themes related to GTF between 2010 and 2019. As presented in Table 1, the three themes include GTF vis-à-vis year (six sub-themes), GTF vis-à-vis types of heritage promotions (six sub-themes) and GTF vis-à-vis ethnicity (five sub-themes). 
Table 1. The main themes and sub-themes

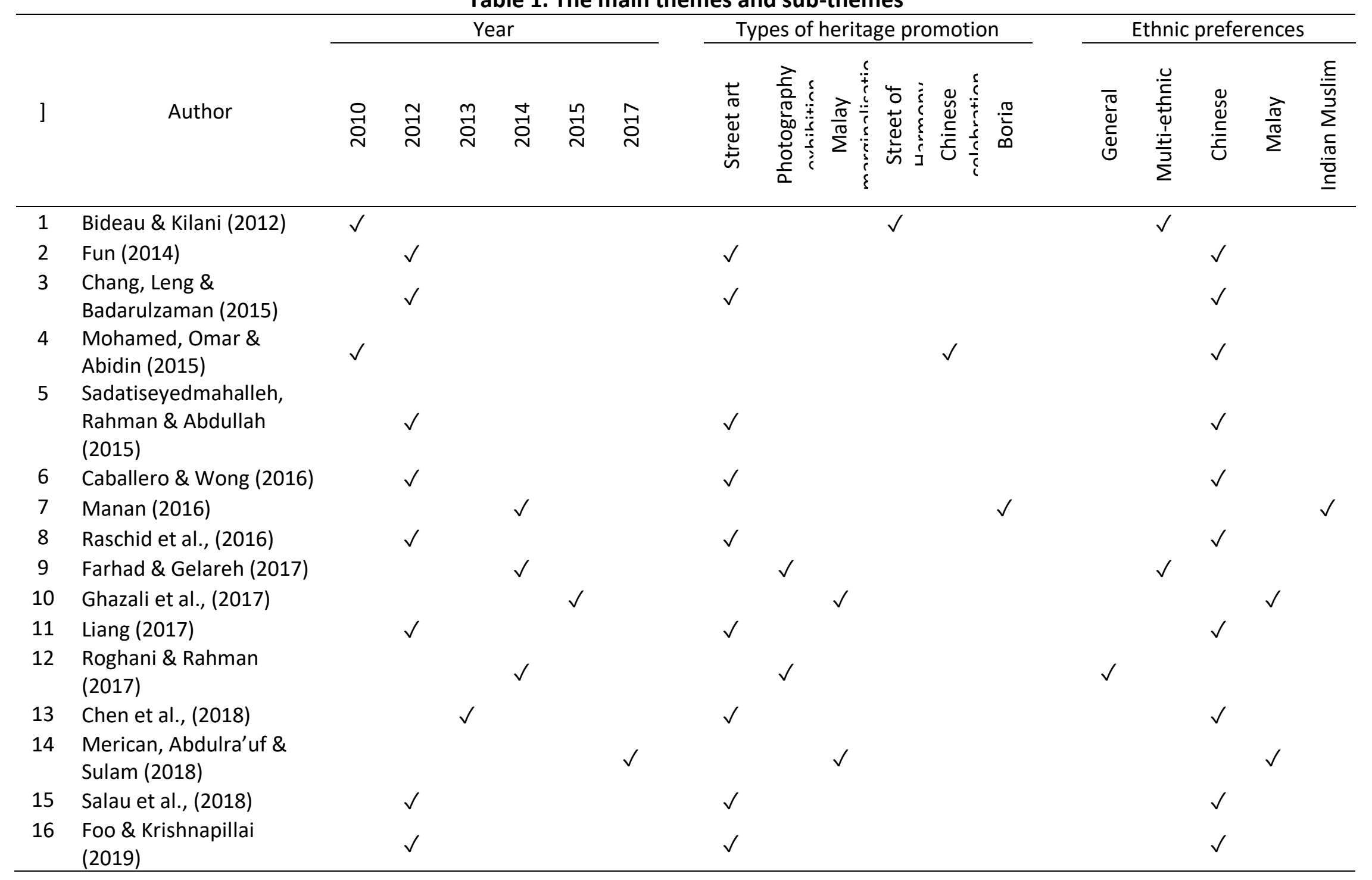


INTERNATIONAL JOURNAL OF ACADEMIC RESEARCH IN BUSINESS AND SOCIAL SCIENCES Vol. 10, No. 5, May, 2020, E-ISSN: 2222-6990 @ 2020 HRMARS

\section{GTF vis-à-vis Year}

As mentioned above, GTF is an annual month-long festival organized to commemorate George Town as UNESCO Cultural World Heritage Site. Since 2010, a total of sixteen previous articles were found to focus on the festival. Specifically, it should be noted that eight previous studies focused on GTF 2012 (Fun, 2014; Chang et al., 2015; Sadatiseyedmahalleh et al., 2015); Caballero \& Wong, 2016; Raschid, Yazah, Tahir, Osman \& Elham, 2016; Liang, 2017; Salau et al, 2018; Foo \& Krishnapillai, 2019), three studies examined GTF 2014 (Manan, 2016; Farhad \& Gelareh, 2017 and Roghani \& Rahman,2017); two studies investigated GTF 2010 (Bideau \& Kilani,2012 and Mohamed et al., 2015) followed by one past research each concentrated on GTF 2013 (Chen et al, 2018), GTF 2015 (Ghazali et al., 2017) and GTF 2017 (Merican, Abdulra'uf \& Sulam, 2018), respectively.

\section{GTF vis-à-vis types of Heritage}

GTF aims to be an international platform for Penang's multi-ethnic community to showcase their local cultural and heritage. Regarding this matter, a number of studies have focused on types of heritage promotions which managed to lead to the emergence of six sub-themes under the GTF vis-à-vis types of heritage promotions theme, that include nine studies on street art (Chang, Leng \& Badarulzaman, 2015, Sadatiseyedmahalleh, Rahman \& Abdullah, 2015, Caballero \& Wong, 2016, Raschid et al., 2016, Liang, 2017, Chen et al., 2018, Salau et al., 2018 and Foo \& Krishnapillai, 2019); two studies regarding photography exhibitions (Farhad \& Gelareh, 2017 and Roghani \& Rahman, 2017), two studies about Malay marginalisation (Ghazali et al., 2017 and Merican, Abdulra' uf \& Sulam, 2018); as well as one study on the Street of Harmony (Bideau \& Kilani, 2012); one study on Chinese celebrations (Mohamed, Omar \& Abidin, 2015) and one study on Boria (Manan, 2016)

\section{GTF vis-à-vis Ethnic Preferences}

George Town was established as a free trading port in 1786. Since then, many traders from neighbouring countries flocked to this country for trading purposes. Some of them settled down and married local women. Hence, the inter-marriage phenomenon shaped the multi-ethnic community of Penang today. A total of five sub-themes were found to focus on GTF vis-à-vis multi-ethnic community in Penang. The analysis for this sub-theme include ten studies of Chinese community (Fun, 2014, Chang, Leng \& Badarulzaman, 2015 Mohamed, Omar \& Abidin, 2015, Sadatiseyedmahalleh, Rahman \& Abdullah, 2015 Caballero \& Wong, 2016 Raschid et al., 2016, Liang, 2017, Chen et al., 2018) and Foo \& Krishnapillai, 2019); followed by two studies on multi-ethnic community (Bideau \& Kilani, 2012 and Farhad \& Gelareh, 2017)); two studies vis-à-vis Malay community (Ghazali et al., 2017 and Merican, Abdulra'uf \& Sulam, 2018); one study with regards to Indian Muslim community (Manan, 2016); as well as one study that did not focus on any ethnic group (Roghani \& Rahman, 2017).

\section{Discussions}

In this section, the heritage promotions of multi-ethnic local community of Penang through the annual inauguration of GTF are grouped into two categories. The first category refers to the positive heritage promotions through GTF where the multi-ethnic local community have an international platform to showcase their culture and heritage. 
This findings is supported by Jaeger \& Mykletun (2013) where festivals may contribute to the development of individual and collective identities, strengthen a sense of cohesiveness and belonging to a place, and also make places more visible, thereby increasing their capacity to attract people. Furthermore, RICHES (2016) research shows that cultural one of the more visible platforms for maintaining cultural connections, creating new friendships and challenging stereotypes is via heritage festivals. This has led to the festival becoming an embodied space in which ideas of belonging, sense of place and identity are transformed and communicated.

Additionally, the second category refers to a negative side of cultural heritage promotions which lacking of other ethnic groups' representation at the festival. Festivals celebrate cultural traditions. Ethnic festivals, in particular, showcase the ethnic culture of communities that have settled in a region due to immigration (McClinchey, 2008). Because of their potential to bring positive economic and social impacts to communities, cultural festivals have become an increasingly central element of city living (Quinn, 2005). For GTF, the findings shows that the ethnic festival is promoted as being "too Chinese". The challenge for many Penang which include tourism regeneration strategies is to integrate the heritage of all ethnic groups not merely the dominant groups who have power (Caffyn \& Lutz, 1999). While certain groups gain and sustain their dominant status through the process of organizing and presenting a community cultural festival, care also needs to be taken for festival organizers to ensure an inclusive cultural representation of all multi-ethnic local community in Penang. This is because problems with representation of places can arise if marginality is brought to attention (Duncan, 1993).

\section{Recommendations}

The findings and systematic review process of the present study have led to a number of recommendations that may be helpful for future studies. First, future scholars should focus on GTF vis-à-vis ethnicity for their future research despite its absence of the studies that focus on both festival and the uniqueness of the multi-ethnic community of Penang. Moreover, it is vital to investigate which ethnic groups have been highly promoted and which ethnic groups have been lacking in terms of representation in showcasing their own culture and heritage at the festival. Moreover, it should be realised that only sixteen studies vis-à-vis GTF are available yet none of the studies have focused on GTF per particular of years. In this case, as GTF is considered an international and well-known cultural heritage festival, it is vital for the future researchers to further investigate GTF and other heritage events and festivals vis-à-vis cultural promotions of multi-ethnic community in Penang.

\section{Conclusion}

The current review of literature on GTF discovers three key themes that include GTF vis-à-vis year, GTF vis-à-vis types of heritage promotion and GTF vis-à-vis ethnicity. The first theme revealed that GTF 2012 studies were dominantly published compared to other GTF between 2010 and 2019. The second theme showed that a number of studies have heavily focused on the heritage promotions of Penang street art. While the third theme indicated that the GTF studies vis-à-vis multi-ethnic local community have greatly emphasized on Chinese community. Overall, the studies on GTF in Penang offers the findings of imbalance representations of Penang's multi-ethnic community and therefore, future studies on other heritage festivals vis-à-vis multi-ethnic local community should be 
INTERNATIONAL JOURNAL OF ACADEMIC RESEARCH IN BUSINESS AND SOCIAL SCIENCES

Vol. 10, No. 5, May, 2020, E-ISSN: 2222-6990 @ 2020 HRMARS

encouraged in order to assist the concerned parties in organizing such heritage festivals in near future.

\section{Acknowledgement}

The author would like to express appreciation to Assoc. Prof. Dr. Reevany Bustami (Universiti Sains Malaysia, Penang) who have helped in supervisory this study.

\section{Corresponding Author}

Dina Miza Suhaimi, (1) Center for Policy Research and International Studies, Universiti Sains Malaysia, Penang, Malaysia; (2) Faculty of Technical and Vocational, Universiti Pendidikan Sultan Idris, 35900, Tanjong Malim, Perak. Email: dinamiza2002@gmail.com

\section{References}

\section{Journal article}

Bideau, F. G., \& Kilani, M. (2012). Multiculturalism, cosmopolitanism, and making heritage in Malaysia: a view from the historic cities of the Straits of Malacca. International Journal of Heritage Studies, 18(6), 605-623.

Caballero, G. \& Wong, K. S. H. (2016). Pop-up Urbanism, a Future for Southeast Asia. International Federation of Landscape Architects (IFLA)

Caffyn, A., \& Lutz, J. (1999). Developing the heritage tourism product in multi-ethnic cities. Tourism Management, 20, 213-221.

Chang, N., Khoo, S. L., \& Badarulzaman, N. (2015). Prospect of Penang as a Creative City: A Conceptual Discussion. International Journal of Cultural and Creative Industries, 3(1).

Chen, S. Y., Piterou, A., Khoo, S. L., \& Chan, J. H. (2018). The Art Hub in the World Heritage Site, Georgetown: A Case Study of Creative Sector Entrepreneurship in the Context of Gentrification.

Duncan, J. S. (1993). Sites of Representation: Place, Time and the Discourse of the Other. In J. Duncan \& D. Ley (Eds.), Place/culture/representation, London: Routledge

Farhad, F., \& Gelareh, A. (2017). Representation of Reality and Local Visitors' Sense of Attachment: The Case of the George Town Festival in Malaysia. Asia-Pacific Journal of Innovation in Hospitality and Tourism, 6(1), 51-64.

Foo, R., \& Krishnapillai, G. (2019). Preserving the Intangible Living Heritage in the George Town World Heritage Site, Malaysia. Journal of Heritage Tourism, 14(4), 358-370.

Fun, C. S. (2014). Street Art Sparkle As A New Economic Driver In Penang. Conference Proceeding: $1^{\text {st }}$ International Conference on Creative Media, Design \& Technology

Ghazali, M. H., Jani, M., Sumrahadi, A., \& Mohamad, B. (2017). The Role of State and Newspaper in Conservation of Historical Site: The Case of Penang. International Journal of Law, Government and Communication, 2(6), 101-113.

Jaeger, K., \& Mykletun, R. J. (2013). Festivals, Identities, and Belonging. Event Management, 17(3), 213-226.

Liang, C. (2017). George Town's Street Mural Art and Tourism Impact. Asian Journal of Tourism Research, 2(3), 168-188.

Manan, S. A. (2016). Boria: Penang's Unique Malay-Islamic Cultural Heritage. KEMANUSIAAN: The Asian Journal of Humanities, 23. 
INTERNATIONAL JOURNAL OF ACADEMIC RESEARCH IN BUSINESS AND SOCIAL SCIENCES

Vol. 10, No. 5, May, 2020, E-ISSN: 2222-6990 @ 2020 HRMARS

McClinchey, K. A. (2008). Urban Ethnic Festivals, Neighborhoods, and the Multiple Realities of Marketing Place. Journal of Travel \& Tourism Marketing, 25(3-4), 251-264.

Merican, A. M., Abdulra'uf, M. Y. U., \& Sulam, M. (2018). The representation of George Town Heritage: A two-space analysis of local alienation. Pertanika Journal of Social Sciences and Humanities, 137-152.

Quinn, B. (2005). Changing Festival Places: Insights from Galway. Social and Cultural Geography, 6(2), 237-252.

Raschid, M., Yazah M., Tahir, M., Osman \& Elham, K. (2016) Public Mural Art Installations In An Urban Cultural District: Place Identity Under Scrutiny. In: STEdex 15/16: Sustainable Tropical Environmental Design Exhibition. Universiti Putra Malaysia Press, Serdang, Selangor, pp. 12-27.

Roghani, F. F., \& Rahman, Z. (2017). Impact of Photography on the Representation of The George Town Heritage Site in Penang, Malaysia. Wacana Seni Journal of Arts Discourse, 16

Sadatiseyedmahalleh, S., Rahman, S., \& Abdullah, A. (2015). Critical Review on the Role of Street Art of George Town, Pulau Pinang. Advances in Environmental Biology, 9(4), 181-184.

Salau, J. A., Abdullah, Q. D. L., Hamid, S. A., \& Jali, A. (2018) Developing A Conceptual Framework ff Street Arts Project in Preserving The Malaysian Culture. Journal of Business and Social Development Volume 6 Number 1: 84-93

Shaffril, H. A. M., Samah, A. A., Samsuddin, S. F., \& Ali, Z. (2019). Mirror-Mirror on the Wall, What Climate Change Adaptation Strategies are Practiced by the Asian's Fishermen of All?. Journal of Cleaner Production.

Wolf, F. M., Shea, J. A., Albanese, M. A. (2001). Toward Setting a Research Agenda for Systematic Reviews of Evidence of the Effects of Medical Education. Teach. Learn. 13, 53-60.

Mohamed, B., Omar, S. I., \& Abidin, S. Z. Z. (2015). The Perils of Tourism Growth in a World Heritage Site: The Case of George Town, Penang. $5^{\text {th }}$ International Conference of Jabodetabek Study Forum, At Bogor, Indonesia

Moher, D., Liberati, A., Tetzlaff, J., Altman, D. G., The PRISMA Group. (2009). Preferred Reporting Items for Systematic Reviews and MetaAnalyses: the PRISMA statement. PLoS Med. 6 (7)

\section{Online Newspaper Articles}

RICHES. (2016) Research Publication E03 Cultural Heritage Festivals: Belonging, Sense of Place and Identity Retrieved from https://www.digitalmeetsculture.net/wpcontent/uploads/2016/04/rch_thinkpapers_03.pdf

Sidek, J. (2011). George Town Festival Facebook Page. Retrieved from

https://georgetownfestival.com/2019/wp-content/uploads/2019/06/GTF-2019-Press-Release_18January-2019-English.pdf

Cultural Transitions: George Town (2012). Retrieved from https://culture360.asef.org/magazine/cultural-transitions-george-town/ 